Journal of Applied Sciences 8 (14): 2523-2533, 2008

ISSN 1812-5654

(C) 2008 Asian Network for Scientific Information

\title{
Quantitative Precipitation Forecast in the Caspian Sea/Alburz Mountain Region: MM5 Verification
}

\author{
${ }^{1}$ Mohammad Oskouian, ${ }^{2}$ Malcolm L. Heron and ${ }^{3}$ Mohammad R. Mobasheri \\ ${ }^{1}$ James Cook University, Townsville, 4811, Australia \\ Hormozgan University, Bandar Abbas, Iran and University of Guilan, Rasht, Iran \\ 2AIMS@JCU and Marine Geophysical Laboratory, James Cook University, Townsville, 4811, Australia \\ ${ }^{3}$ K.N. Toosi University of Technology, Tehran, Iran
}

\begin{abstract}
This study presents verification of QPF of a Mesoscale Modelling system (Pennsylvania State University/NCAR Fifth generation MM5) in the region bounded by southern shores of Caspian Sea and northern slopes of the Alburz Mountains in Iran, against the selected observation site's rainfall data for the 59 day period on September and October 2004. The choice of MM5 parameterization schemes follows the results of a previous sensitivity test in the region. The MM5 forecasts of light and moderate precipitation thresholds are more accurate than the heavy precipitation threshold. Analysis of the bias scores shows that MM5 has a tendency to forecast higher number of rainy events in lower rain thresholds at the selected observation points. Equitable treat scores show that except for some isolated points in the light rain threshold the $9 \mathrm{~km}$ domain produces better forecasts than the $27 \mathrm{~km}$ domain. The nearest grid point approximation in most cases produced better precipitation forecasts than the Cressman weighted average interpolation.
\end{abstract}

Key words: Mesoscale, QPF, MM5, Caspian, Alburz, verification, bias, ETS

\section{INTRODUCTION}

This is the second paper in a series examining Pennsylvania State University-National Center for Atmospheric Research (PSU-NCAR) fifth-generation Mesoscale Modelling System (MM5) Quantitative Precipitation Forecasts (QPF) over the Caspian Sea/Alburz Mountains region in Southwest Asia. The first part of this series (Oskouian et al., unpublished data) examined two rainfall events at 7 September and 13 October 2004 by performing sensitivity tests of MM5 $24 \mathrm{~h}$ forecasts against the raingauge data of Iranian Meteorological Organization (IMO) selected stations in the Caspian/Alburz region. According to findings of the first part a 3 domain 81, 27 and $9 \mathrm{~km}$ model with AnthesKuo, Grell and Kain-Fritsch cumulus parameterizations respectively and with warm rain explicit moisture scheme in the warm season and Reisner mixed-phase scheme in the cold season gives better predictions for the rainfall intensity at point locations. On the other hand performing a FDDA run and increasing the resolution to $3 \mathrm{~km}$ showed no clear advantage over the previous runs. We use the results of those sensitivity tests for verification of the $24 \mathrm{~h}$ MM5 forecasts in a 59 days period in the Caspian/Alburz region.
The PSU/NCAR MM5 is a limited-area nonhydrostatic model that uses a terrain-following vertical coordinate system (Dudhia, 1993; Grell et al., 1994). It has 2-way nesting capabilities and flexible physics options. We compiled version 3.6 using intel suite of compilers on a Redhat 9 Linux box using $3.6 \mathrm{GHz}$ CPU and 1 MB RAM.

MM5 has been extensively used for case studies of mesoscale orographic rainfalls (Litta et al., 2007; Juneng et al., 2007; Chiao et al., 2004; Lin et al., 2001; Hayes et al., 2002; Lou et al., 2001; Paolucci et al., 1999; Chen et al., 1998), simulation of mesoscale convective systems (Zhang et al., 2000, 2003), investigation of topography effects on the formation and intensification of convective systems (Peng et al., 2001; Lin and Chen, 2002) and the verification of QPFs (Colle et al., 2000; Chien et al., 2002).

We defined three domains at the site with dimensions 81,27 and $9 \mathrm{~km}$, respectively (Fig. 1) and ran $24 \mathrm{~h}$ simulations of MM5 for the 23 vertical sigma levels in these domains and for two months of September and October 2004 initialized by NCEP Global Tropospheric Analysis 6 hourly $1 \times 1$ resolution dataset and using NCEP Real Time Global Sea Surface high resolution daily Temperatures.

Corresponding Author: Mohammad Oskouian, Department of Physics, University of Guilan, Rasht 41335-1911, Iran Tel: +98911 1844073 Fax: +981313220066 


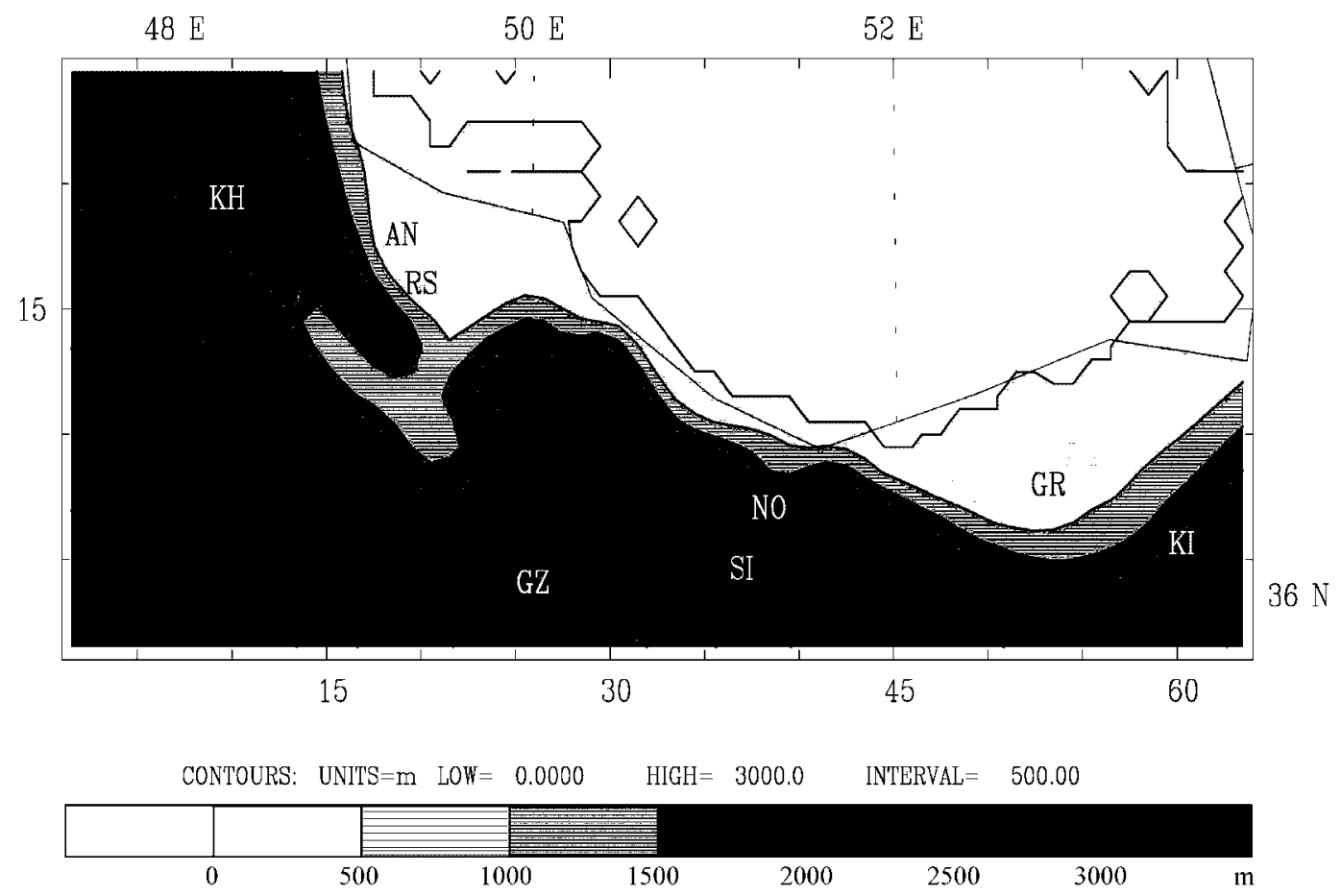

Fig. 1: The MM5 $9 \mathrm{~km}$ domain over Caspian/Alburz region in Iran showing synoptic station locations and their approximate elevations. The selected stations (exact elevation in meters above mean sea level) are: ANzali (-26), NOeshahr (-21), RaSht (-7), GaRakhil (+15), KIasar $(+1294)$, SIabisheh $(+2165)$

In this study MM5 was implemented with a) the MRF PBL parameterization scheme (Hong and Pan, 1996), b) the Rapid Radiative Transfer Model (RRTM) radiation scheme (Malwer et al., 1997), c) the Warm Rain explicit moisture parameterization scheme for the September runs and the Reisner Mixed-Phase scheme (Reisner et al., 1998) for the October runs and d) the following Cumulus Parameterizations: Anthes-Kuo scheme for $81 \mathrm{~km}$ domain, the Grell Cumulus scheme for the $27 \mathrm{~km}$ domain (Grell et al., 1994), the Kain-Fritsch 2 scheme for the $9 \mathrm{~km}$ domain (Kain and Fritsch, 1993; Kain, 2002) according to the results presented in Oskouian et al. (unpublished data).

\section{MATERIALS AND METHODS}

Site description: The region in south west Asia roughly between $30^{\circ} \mathrm{N}$ to $45^{\circ} \mathrm{N}$ and $40^{\circ} \mathrm{E}$ to $60^{\circ} \mathrm{E}$ (Fig. 2) is the main area and the narrow strip between the Alburz mountain range and the Caspian Sea in Iran is the focus of this study. The Alburz range is an east-west wall of mountains with broad areas above $2500 \mathrm{~m}$ elevation and some isolated peaks reaching up to $5600 \mathrm{~m}$. The Caspian Sea (technically a lake) extends from $36^{\circ} \mathrm{N}$ to $47^{\circ} \mathrm{N}(\sim 1200 \mathrm{~km})$ with an average width of $300 \mathrm{~km}$ and it's surface lies more than $20 \mathrm{~m}$ below mean sea level. We call this narrow coastal strip between the inland sea and the mountains here the Caspian/Alburz region. Moisture from the Caspian Sea and the orographic lift of the Alburz wall is considered a main factor to produce the highest rainfall rate in Iran for this region, creating a wet $(1300-2000 \mathrm{~mm} /$ year) zone in the otherwise dry ( $-500 \mathrm{~mm} /$ year) plateau of Iran (Wikipedia, 2006). We used high temporal resolution rainfall data from selected synoptic stations (Fig. 2) in this area for the months September and October 2004 to verify the MM5 modelling system $24 \mathrm{~h}$ precipitation forecasts.

Methodology: As the observing network resolution in the Caspian/Alburz region is considerably lower than the model resolution (Fig. 2), we use an inverse distance Cressman method (Cressman, 1959; Stephens and Stitt, 1970) to interpolate the precipitation from the model grid to each observation site: 


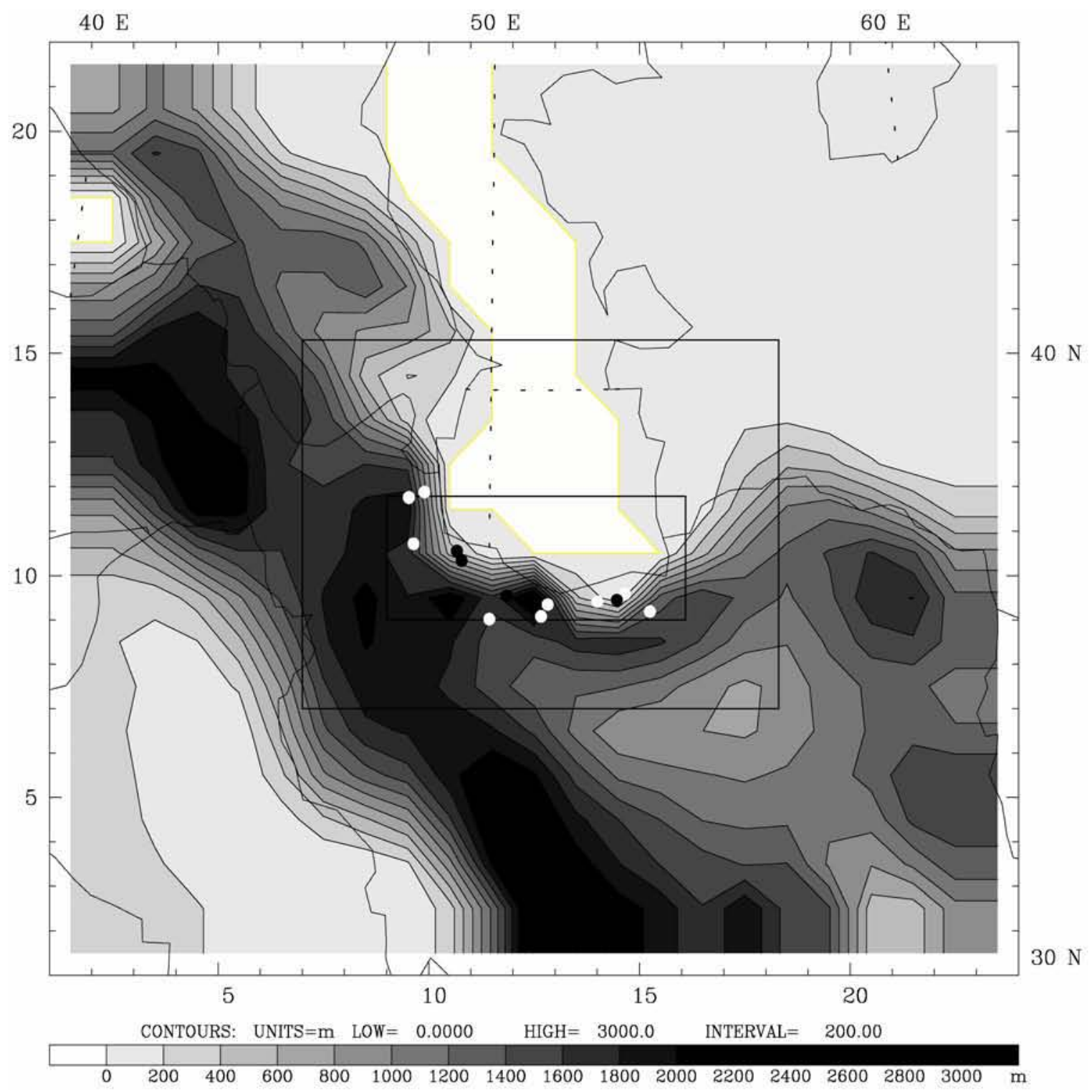

Fig. 2: The south west Asia region with three MM5 domains 81, 27, $9 \mathrm{~km}$ focusing on Caspian/Alburz region in Iran. Circles show synoptic stations of Iranian Meteorological Organization with available high temporal resolution rainfall data at the time of study

$$
\mathrm{P}=\frac{\sum \mathrm{W}_{\mathrm{n}} \mathrm{P}_{\mathrm{n}}}{\sum \mathrm{W}_{\mathrm{n}}}
$$

where, $P_{n}$ is the model precipitation at a number of adjacent grid points surrounding the observation. A parameter controls this number and depending on the location of observation inside the domain $\mathrm{n}$ is from 4 to 6 . The weight $\mathrm{W}_{\mathrm{n}}$ given to the surrounding grid point values is given by:

$$
\mathrm{W}_{\mathrm{n}}=\frac{\mathrm{R}^{2}-\mathrm{D}_{\mathrm{n}}^{2}}{\mathrm{R}^{2}-\mathrm{D}_{\mathrm{n}}^{2}}
$$

where, $\mathrm{R}$ is the model horizontal grid spacing and $\mathrm{D}$ is the horizontal distance from the model grid point to the observation. As a kind of smoothing of the model results in this approach is always expected, we also applied the nearest grid point value directly to the observation in the fine $9 \mathrm{~km}$ domain and in the figure 
legends labelled it $\mathrm{n} 9 \mathrm{~km}$ in contrast to $\mathrm{c} 9 \mathrm{~km}$ and $27 \mathrm{~km}$ for the Cressman values in the two respective domains.

We use contingency table approach following (Wilks, 1995). For a set of observations and dichotomous (yes/no) forecasts we may have a number of Hits $(H)$, Misses (M), False Alarms (FA) and Correct Negatives (CN) and the sum of them all as Total (T) then a measure of Accuracy of the forecast is defined as:

$$
\mathrm{Acc}=\frac{\mathrm{H}+\mathrm{CN}}{\mathrm{T}}
$$

Bias score measures the ratio of the frequency of forecasted to observed event and is defined as:

$$
\mathrm{B}=\frac{\mathrm{H}+\mathrm{FA}}{\mathrm{H}+\mathrm{M}}
$$

It reveals systematic over- $(>1)$ or under- $(<1)$ prediction by the model.

Equitable Treat Score measures the fraction of observed events that were correctly predicted, adjusted for the hits associated with random chance and is defined by:

$$
\mathrm{ETS}=\frac{\mathrm{H}-\mathrm{HR}}{\mathrm{H}+\mathrm{M}+\mathrm{FA}-\mathrm{HR}}
$$

where Random Hits (HR) is given by:

$$
\mathrm{HR}=\frac{(\mathrm{H}+\mathrm{M})(\mathrm{H}+\mathrm{FA})}{\mathrm{T}}
$$

Heidke skill score measures the fraction of the correct forecasts after eliminating those forecasts which would be correct due purely to random chance and is defined by:

$$
\mathrm{HSS}=\frac{(\mathrm{H}+\mathrm{CN})-\mathrm{REC}}{\mathrm{T}-\mathrm{REC}}
$$

where Random Expected Correct is given by:

$$
\mathrm{REC}=\frac{(\mathrm{H}+\mathrm{M})(\mathrm{H}+\mathrm{FA})+(\mathrm{CN}+\mathrm{M})(\mathrm{CN}+\mathrm{FA})}{\mathrm{T}}
$$

These scores are easily generalized for a multicategory forecast in which for instance the numerator of Bias score will be the number of forecasts at the observation stations with precipitation equal to or exceeding a given threshold amount and the denominator the number of occurrences in which the observations meet or exceed the threshold. In this study we setup a $4 \times 4$ contingency table with the categories being heavy
$(>10 \mathrm{~mm})$, moderate $(>2.5 \mathrm{~mm})$, light $(>0.3 \mathrm{~mm})$ and dry $(<0.3 \mathrm{~mm})$. Each MM5 run starts at 00.00 UTC and ends at 00.00 UTC of the next day. Rainfall accumulation period is $6 \mathrm{~h}$ and computed for lead times 12,18 and 24 .

\section{RESULTS AND DISCUSSION}

Figure 3 and 4 show bias scores for MM5 QPFs applied to observation sites mentioned in the titles using Cressman interpolation in the $27 \mathrm{~km} \mathrm{(27)} \mathrm{and} 9 \mathrm{~km} \mathrm{(c9)}$ domains and nearest grid point method in $9 \mathrm{~km}$ (n9) domain for the September and October 2004 period. Accuracies for each domain and scheme are shown in the legends.

Figure 5 and 6 show equitable treat scores for MM5 QPFs applied to observation sites mentioned in the titles using Cressman interpolation (27 and c9) and nearest grid point (n9) for the same two months period. Heidke skill scores for each domain and scheme are shown in the legends. Six hours accumulated rain is computed for lead times shown in the titles of Fig. 3-6.

The exact numbers of all the scores of the figures are shown in the Table 1-6. Bias scores for the QPF lead times 12,18 and $24 \mathrm{~h}$ are presented in Table 1-3, respectively. Equitable treat scores for the same QPF lead times are displayed in Table 4-6.

Accuracies: Figure $3 \mathrm{f}$ and c show more accurate $\mathrm{n} 9$ than c9 for Anzali and Siabisheh but Cressman method show more accurate in Gharakhil (Fig. 4d), Noeshahr (Fig. 4b) and Kiasar (Fig. 4e). This can be explained by existence of a more nearby grid point to the locations of Anzali and Siabisheh. All three schemes show drop in accuracy by increase in forecast lead times (Fig. 3, 4).

\section{Bias scores}

Light rain: Rainfall category 2 (0.3 to $2.5 \mathrm{~mm}$ ) represents light rain. This category clearly over-predicted in almost all stations for all schemes (Fig. 3, 4) except unbiased n9 in Gharakhil (Fig. 4c, d). This over-prediction intensifies with lead time increase (Fig. 3). The $\mathrm{n} 9$ scheme exhibits weaker over-prediction in all stations (Fig. 3, 4) except in high-level Siabisheh which $\mathrm{c} 9$ have weakest overprediction (Fig. 4f).

Moderate rain: Rainfall category $3(2.5$ to $10 \mathrm{~mm}$ ) represents moderate rain. All three schemes show overprediction in this category. Although $n 9$ slightly reduces over-prediction but $\mathrm{c} 9$ and 27 schemes show more overprediction with lead time (Fig. 3). We face slightly negative or slightly positive bias for all schemes in other stations (Fig. 4). This is the most unbiased category. 

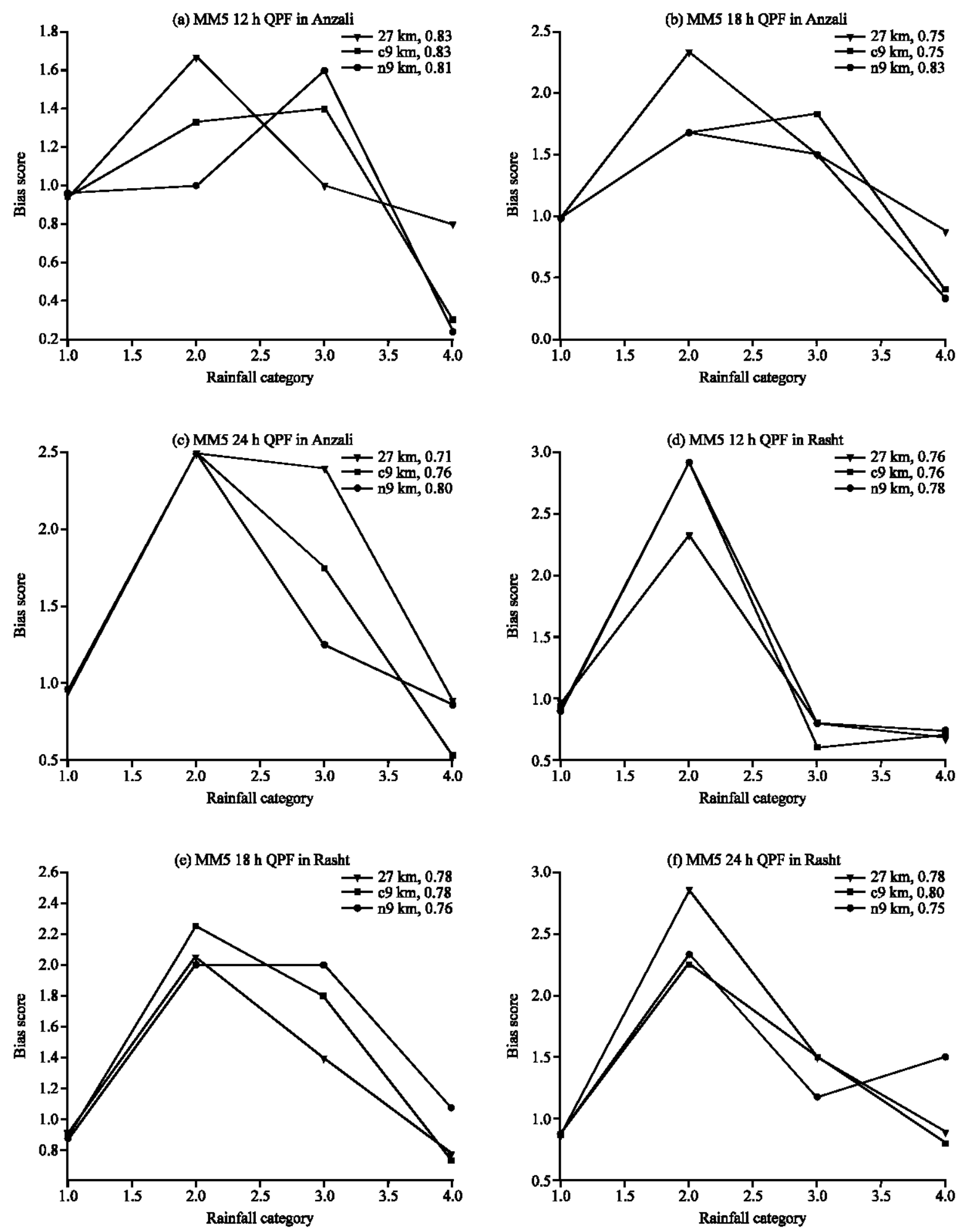

Fig. 3: Bias scores for MM5 QPFs applied to observation sites Anzali and Rasht using Cressman interpolation in the domains 27 and $9 \mathrm{~km}$ and nearest grid point method in $9 \mathrm{~km}$ domain for the September and October 2004 period. Six hour accumulated rain is computed for lead times shown on the titles. Accuracies are shown in the legends 

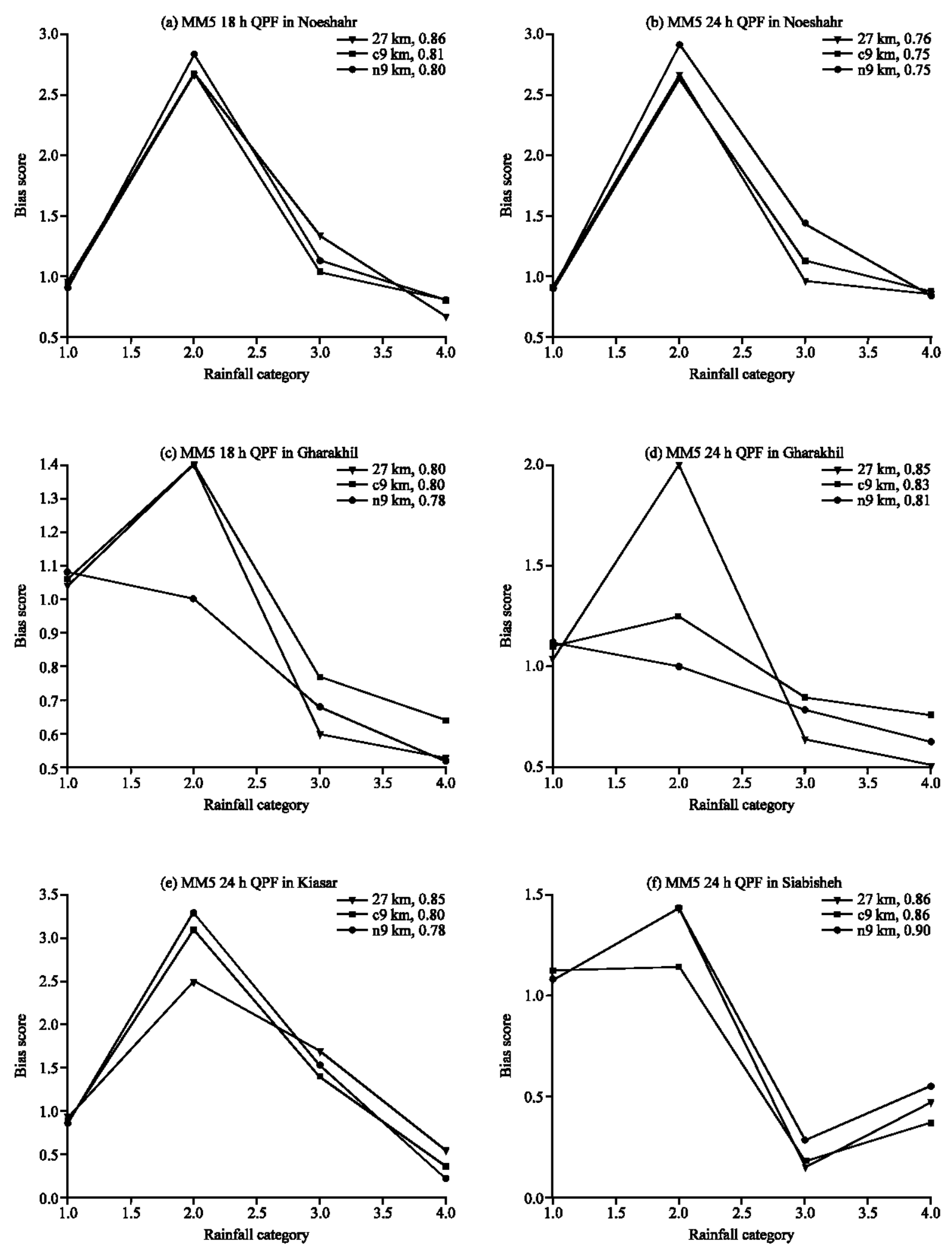

Fig. 4: Same as Fig. 3 but for other observation sites mentioned on the titles 

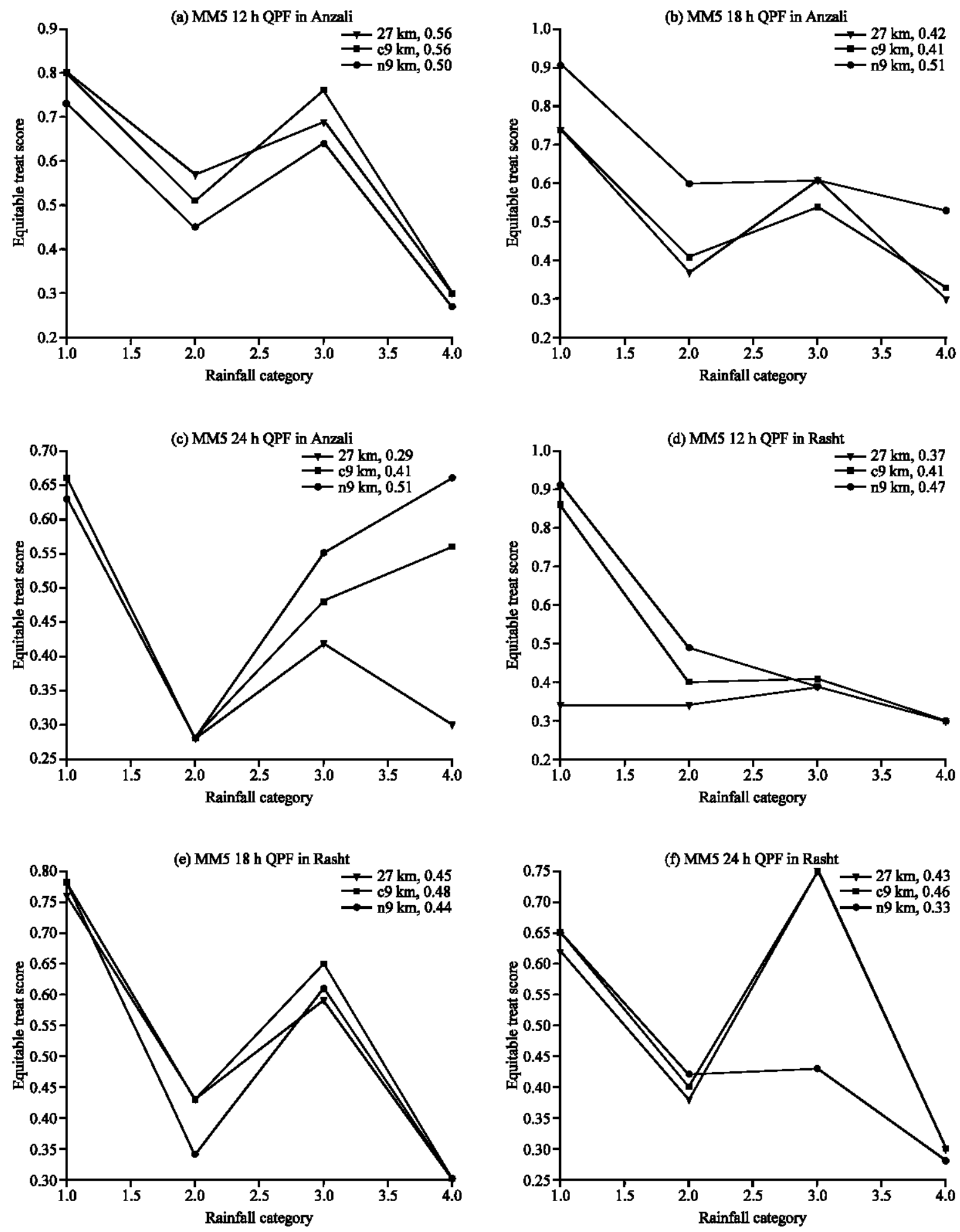

Fig. 5: Equitable treat scores for MM5 QPFs applied to observation sites Anzali and Rasht using Cressman interpolation in the domains 27 and $9 \mathrm{~km}$ and nearest grid point method in $9 \mathrm{~km}$ domain for the September and October 2004 period. Six hour accumulated rain is computed for lead times shown on the titles. Heidke skill scores are shown in the legends 

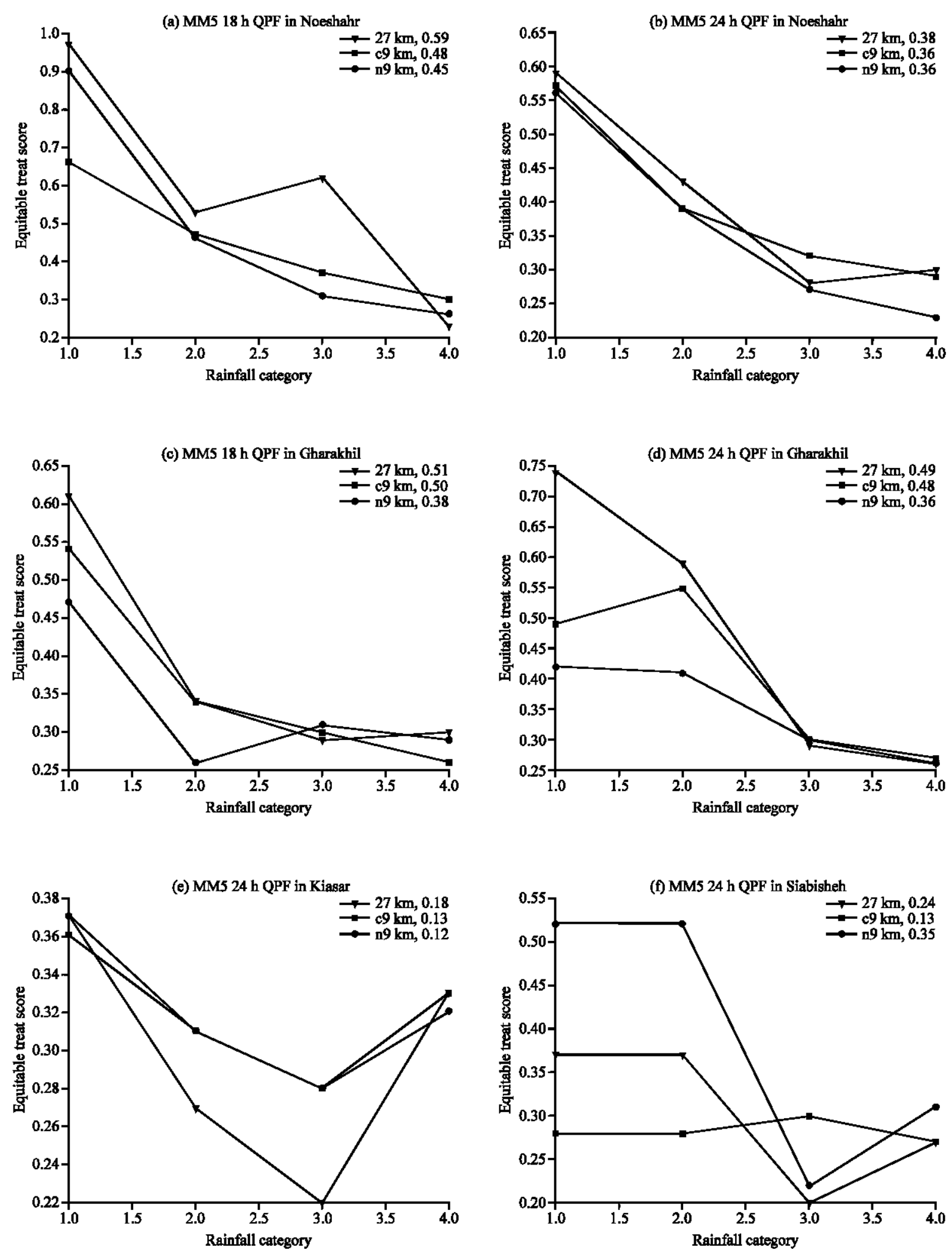

Fig. 6: Same as Fig. 5 but for other observation sites mentioned on the titles 
Table 1: Twelve hours QPF Bias scores in rainfall categories dry, light, moderate and heavy and for different MM5 schemes in selected stations in Caspian-Alburz region

\begin{tabular}{lcccc}
\hline & Dry & Light & Mod & Heavy \\
\hline Anzali & & & & \\
27 & 0.94 & 1.67 & 1.00 & 0.80 \\
c9 & 0.94 & 1.33 & 1.40 & 0.30 \\
n9 & 0.96 & 1.00 & 1.60 & 0.24 \\
Rasht & & & & \\
27 & 0.96 & 2.33 & 0.80 & 0.67 \\
c9 & 0.91 & 2.92 & 0.60 & 0.70 \\
n9 & 0.89 & 2.92 & 0.80 & 0.73 \\
\hline
\end{tabular}

Table 2: Eighteen hours QPF bias scores in rainfall categories dry, light, moderate and heavy and for different MM5 schemes in selected stations in Caspian-Alburz region

\begin{tabular}{lllll}
\hline & Dry & Light & Mod & Heavy \\
\hline Anzali & & & & \\
27 & 0.98 & 2.33 & 1.50 & 0.87 \\
c9 & 0.98 & 1.67 & 1.83 & 0.40 \\
n9 & 0.98 & 1.67 & 1.50 & 0.33 \\
Rasht & & & & \\
27 & 0.91 & 2.05 & 1.40 & 0.77 \\
c9 & 0.87 & 2.25 & 1.80 & 0.73 \\
n9 & 0.87 & 2.00 & 2.00 & 1.07 \\
Gharakhil & & & & \\
27 & 1.04 & 1.40 & 0.60 & 0.53 \\
c9 & 1.06 & 1.40 & 0.77 & 0.64 \\
n9 & 1.08 & 1.00 & 0.68 & 0.52 \\
Noeshahr & & & & \\
27 & 0.96 & 2.67 & 1.33 & 0.67 \\
c9 & 0.92 & 2.67 & 1.03 & 0.80 \\
n9 & 0.90 & 2.83 & 1.13 & 0.80 \\
\hline
\end{tabular}

Table 3: Twenty four hours QPF bias scores in rainfall categories dry, light, moderate and heavy and for different MM5 schemes in selected stations in Caspian-Alburz region

\begin{tabular}{lllll}
\hline & Dry & Light & Mod & Heavy \\
\hline Anzali & & & & \\
27 & 0.96 & 2.50 & 2.40 & 0.89 \\
c9 & 0.96 & 2.50 & 1.75 & 0.53 \\
n9 & 0.93 & 2.50 & 1.25 & 0.86 \\
Rasht & & & & \\
27 & 0.86 & 2.85 & 1.50 & 0.89 \\
c9 & 0.88 & 2.25 & 1.50 & 0.80 \\
n9 & 0.88 & 2.33 & 1.17 & 1.50 \\
Gharakhil & & & & \\
27 & 1.04 & 2.00 & 0.64 & 0.51 \\
c9 & 1.10 & 1.25 & 0.85 & 0.76 \\
n9 & 1.12 & 1.00 & 0.79 & 0.63 \\
Noeshahr & & & & \\
27 & 0.92 & 2.67 & 0.97 & 0.85 \\
c9 & 0.90 & 2.63 & 1.13 & 0.88 \\
n9 & 0.90 & 2.92 & 1.44 & 0.84 \\
Siabisheh & & & & \\
27 & 1.08 & 1.43 & 0.15 & 0.47 \\
c9 & 1.12 & 1.14 & 0.18 & 0.37 \\
n9 & 1.08 & 1.43 & 0.28 & 0.55 \\
Kiasar & & & & \\
27 & 0.93 & 2.50 & 1.70 & 0.55 \\
c9 & 0.88 & 3.10 & 1.40 & 0.36 \\
n9 & 0.86 & 3.30 & 1.53 & 0.22 \\
\hline
\end{tabular}

Heavy rain: Rainfall category $4(>10 \mathrm{~mm})$ represents heavy rain. This category is under-predicted at all lead times and for all schemes (Fig. 3,4). It does not change with lead time in $27 \mathrm{~km}$ scheme (Fig. 3) but we experience
Table 4: Twelve hours QPF ETS scores in rainfall categories dry, light, moderate and heavy and for different MM5 schemes in selected stations in Caspian-Alburz region

\begin{tabular}{lcccc}
\hline & Dry & Light & Mod & Heavy \\
\hline Anzali & & & & \\
27 & 0.80 & 0.57 & 0.69 & 0.30 \\
c9 & 0.80 & 0.51 & 0.76 & 0.30 \\
n9 & 0.73 & 0.45 & 0.64 & 0.27 \\
Rasht & & & & \\
27 & 0.34 & 0.34 & 0.39 & 0.30 \\
c9 & 0.86 & 0.40 & 0.41 & 0.30 \\
n9 & 0.91 & 0.49 & 0.39 & 0.30 \\
\hline
\end{tabular}

Table 5: Eighteen hours QPF ETS scores in rainfall categories dry, light, moderate and heavy and for different MM5 schemes in selected stations in Caspian-Alburz region

\begin{tabular}{|c|c|c|c|c|}
\hline & Dry & Light & Mod & Heavy \\
\hline \multicolumn{5}{|c|}{ Anzali } \\
\hline 27 & 0.74 & 0.37 & 0.61 & 0.30 \\
\hline$c 9$ & 0.74 & 0.41 & 0.54 & 0.33 \\
\hline n9 & 0.91 & 0.60 & 0.61 & 0.53 \\
\hline \multicolumn{5}{|c|}{ Rasht } \\
\hline 27 & 0.76 & 0.43 & 0.59 & 0.30 \\
\hline c9 & 0.78 & 0.43 & 0.65 & 0.30 \\
\hline n9 & 0.78 & 0.34 & 0.61 & 0.30 \\
\hline \multicolumn{5}{|c|}{ Gharakhil } \\
\hline 27 & 0.61 & 0.34 & 0.29 & 0.30 \\
\hline c9 & 0.54 & 0.34 & 0.30 & 0.26 \\
\hline n9 & 0.47 & 0.26 & 0.31 & 0.29 \\
\hline \multicolumn{5}{|c|}{ Noeshahr } \\
\hline 27 & 0.97 & 0.53 & 0.62 & 0.23 \\
\hline c9 & 0.66 & 0.47 & 0.37 & 0.30 \\
\hline n9 & 0.90 & 0.46 & 0.31 & 0.26 \\
\hline
\end{tabular}

Table 6: Twenty four hours QPF ETS scores in rainfall categories dry, light, moderate and heavy and for different MM5 schemes in selected stations in Caspian-Alburz region

\begin{tabular}{|c|c|c|c|c|}
\hline & Dry & Light & Mod & Heavy \\
\hline \multicolumn{5}{|c|}{ Anzali } \\
\hline 27 & 0.66 & 0.28 & 0.42 & 0.30 \\
\hline$c 9$ & 0.66 & 0.28 & 0.48 & 0.56 \\
\hline n9 & 0.63 & 0.28 & 0.55 & 0.66 \\
\hline \multicolumn{5}{|c|}{ Rasht } \\
\hline 27 & 0.62 & 0.38 & 0.75 & 0.30 \\
\hline c9 & 0.65 & 0.40 & 0.75 & 0.30 \\
\hline n9 & 0.65 & 0.42 & 0.43 & 0.28 \\
\hline \multicolumn{5}{|c|}{ Gharakhil } \\
\hline 27 & 0.74 & 0.59 & 0.29 & 0.26 \\
\hline c9 & 0.49 & 0.55 & 0.30 & 0.27 \\
\hline n9 & 0.42 & 0.41 & 0.30 & 0.26 \\
\hline \multicolumn{5}{|c|}{ Noeshahr } \\
\hline 27 & 0.59 & 0.43 & 0.28 & 0.30 \\
\hline c9 & 0.57 & 0.39 & 0.32 & 0.29 \\
\hline n9 & 0.56 & 0.39 & 0.27 & 0.23 \\
\hline \multicolumn{5}{|c|}{ Siabisheh } \\
\hline 27 & 0.37 & 0.37 & 0.20 & 0.27 \\
\hline c9 & 0.28 & 0.28 & 0.30 & 0.27 \\
\hline n9 & 0.52 & 0.52 & 0.22 & 0.31 \\
\hline \multicolumn{5}{|c|}{ Kiasar } \\
\hline 27 & 0.37 & 0.27 & 0.22 & 0.33 \\
\hline c9 & 0.36 & 0.31 & 0.28 & 0.33 \\
\hline n9 & 0.37 & 0.31 & 0.28 & 0.32 \\
\hline
\end{tabular}

weaker under-prediction ( 0.8 to 0.3 in $\mathrm{n} 9$ ) with lead time in c9 and n9 to the extent that in Rasht (Fig. 3d, e) we see the only over-prediction (1.4) in $\mathrm{n} 9$. High level stations like Siabisheh (Fig. 4f) show intense under-prediction of heavy rain. 
Heidke skill scores: The Heidke skill score show a higher skill for $n 9$ in Anzali (Fig. 5c) and Siabisheh (Fig. 6f) by the same reasoning mentioned in accuracy section. Cressman method gives similar higher skills for Rasht (Fig. 5f), Noeshahr (Fig. 6b) and Gharakhil (Fig. 6d). In Kiasar we have more skill for $27 \mathrm{~km}$ (Fig. 6d) which it's highly elevated $(+1294 \mathrm{~m})$ and steep slope mountainous location may explain this higher skill. All three schemes show decrease in Heidke skill score with increase in forecast lead time in Noeshahr (Fig. 6a, b) and Gharakhil (Fig. 6c, d) and a slight decrease in Rasht specially from $18-24 \mathrm{~h}$ (Fig. 5d-f) and decrease or no change in Anzali (Fig. 5c).

\section{Equitable Treat Scores (ETS) \\ Light rain: Cressman method has higher ETS values for $27 \mathrm{~km}$ (Fig. 6b, d) and for c9 (Fig. 5c, f, e). n9 only dominates Cressman in the high-level station Siabisheh (Fig. 6f). ETS generally reduces with lead time increase (Fig. 5a-c).}

Moderate rain: ETS reduces with lead time in most of the stations (Fig. 5a-c, 6a, b). Cressman method shows good performance in almost all stations except in Anzali (Fig. 5c). c9 generally gets higher ETS values (Fig. 6b, e, f).

Heavy rain: This category has clearly the lowest ETS values relative to moderate and light rain categories (Fig. 5,6). ETS does not show considerable change with lead time except an increase with lead time in Anzali (Fig. 5a-c). n9 shows clear advantage over Cressman method in Anzali and Siabisheh (Fig. 5c, 6f) but c9 has slightly better performance in almost all other stations.

\section{CONCLUSION}

The bias scores are closer to one for higher rain thresholds so the model seems to forecast a higher number of rainy events than observed events for lower rain thresholds. The MM5 forecasts of light and moderate thresholds of precipitation are more accurate than the heavy thresholds. The $9 \mathrm{~km}$ domain generally produces better QPFs. However for light rain threshold in some stations $27 \mathrm{~km}$ gives better forecasts which may be explained by double penalty problem (Bougeault, 2003). In most cases the nearest grid point approximation produces better forecasts for isolated points than a weighted average interpolation like Cressman method.

This verification can be used as a background analysis for further verification of mesoscale models against higher resolution observations in the Caspian/Alburz region.

\section{ACKNOWLEDGMENTS}

The data (ds083.2, ds464.0, ds353.4) were provided by the Data Support Section of the Scientific Computing Division at the National Center for Atmospheric Research. NCAR is supported by grants from the National Science Foundation. The National Center for Environmental Prediction/Marine Modeling and Analysis Branch (NCEP/MMAB) were provided the Real-Time Global Sea Surface Temperature (RTG_SST) data. The rain gauge data were provided by Iranian Meteorological Organization. We would like to thank Guilan and Hormozgan Universities in Iran, James Cook University in Australia for the computational facilities.

\section{REFERENCES}

Bougeault, P., 2003. The WGNE survey of verification method for numerical prediction of weather elements and severe weather events. Meteo France, Toulouse, pp: 14.

Chen, S.J., Y.H. Kuo, W. Wang, Z.Y. Tao and B. Cui, 1998. A modeling case study of heavy rainstorms along the Mei-Yu front. Mon. Wea. Rev., 126 (9): 2330-2351.

Chiao, S., Y.N. Lin and M.L. Kaplan, 2004. Numerical study of the orographic forcing of heavy precipitation during MAP IOP-2B. Mon. Wea. Rev., 132 (9): 2184-2203.

Chien, F.C., Y.H. Kuo and M.J. Yang, 2002. Precipitation forecast of MM5 in the Taiwan area during the 1998 Mei-yu season. Wea. Forecasting, 17 (4): 739-754.

Colle, B.A., C.F. Mass and K.J. Westrick, 2000. MM5 precipitation verification over the Pacific Northwest during the 1997-99 cool seasons. Wea. Forecasting, 15 (6): 730-744.

Cressman, G.P., 1959. An operational objective analysis system. Mon. Wea. Rev., 87 (10): 367-374.

Dudhia, J., 1993. A nonhydrostatic version of the Penn State/NCAR mesoscale model: Validation tests and simulation of an Atlantic cyclone and cold front. Mon. Wea. Rev., 121 (5): 1493-1513.

Grell, G.A., J. Dudhia and D.R. Stauffer, 1994. A description of the fifth-generation Penn State/NCAR mesoscale model (MM5). NCAR Tech. Note, NCAR/TN-398+STR NCAR, pp: 117.

Hayes, P.S., L.A. Rasmussen and H. Conway, 2002. Estimating precipitation in the central cascades of Washington. J. Hydrometeor, 3 (3): 335-346.

Hong, S.Y. and H.L. Pan, 1996. Nonlocal boundary layer vertical diffusion in a medium-range forecast model. Mon. Wea. Rev., 124 (10): 2322-2339. 
Juneng, L., F.T. Tangang and C.J.C. Reason, 2007. Numerical case study of an extreme rainfall event during 9-11 December 2004 over the east coast of Peninsular Malaysia. Meteor. Atmos. Phys., $98(1-2): 81-98$.

Kain, J.S. and J.M. Fritsch, 1993. Convective parameterization for mesoscale model: The KainFritsch scheme. The representation of cumulus convection in numerical models. Meteor. Monogr., Ame. Meteor. Soc., 24: 165-170.

Kain, J.S., 2002. The Kain-Fritsch convective parameterization: An update. J. Applied Meteor., 43 (1): 170-181.

Lin, C.Y. and C.S. Chen, 2002. A study of orographic effects on mountain-generated precipitation systems under weak synoptic forcing. Meteor. Atmos. Phys., $81(1-2): 1-25$.

Lin, Y.L., S. Chiao, T.A. Wang, M.L. Kaplan and R.P. Weglarz, 2001. Some common ingredients for heavy orographic rainfall. Wea. Forecasting, $16(6)$ : 633-660.

Litta, A.J., B. Chakrapani and K. Mohankumar, 2007. Mesoscale simulation of an extreme rainfall event over Mumbai, India, using a high-resolution MM5 model. Meteor. Applied, 14 (3): 291-295.

Lou, X.F., Z.J. Hu, Y.Q. Shi, P.Y. Wang and X.J. Zhou, 2001. Numerical simulations of a heavy rainfall case in South China. Adv. Atmos. Sci., 20 (1): 128-138.

Malwer, E.J., S.J. Taubman, P.D. Brown, M.J. Iacono and S.A. Clough, 1997. Radiative transfer for inhomogenious atmosphere: RRTM, a validated correlated-k model for the longwave. J. Geophys. Res., 102: 16663-16682.
Paolucci, T., L. Bernardini, R. Ferretti and G. Visconti, 1999. MM5 real-time forecast of a catastrophic event on May, 5, 1998. Nuovo Cimiento Della Societa Italiana Di Fisica C-Geophys. Space Phys., 22 (5): 727-736.

Peng, M.S., J.H. Powell, R.T. Williams and B.F. Jeng, 2001. Boundary layer effects on fronts over topography. J. Atmos. Sci., 58 (15): 2222-2239.

Reisner, J., R.J. Rasmussen and R.T. Bruintjes, 1998. Explicit forecasting of supercooled liquid water in winter storms using the MM5 mesoscale model. Quart. J. Roy. Meteor. Soc., 124B (548): 1071-1107.

Stephens, J.J. and J.M. Stitt, 1970. Optimum influence radii for interpolation with the method of successive corrections. Mon. Wea. Rev., 98 (9): 680-687.

Wikipedia, 2006. http://en.wikipedia.org/wiki/Alburz and http://en.wikipedia.org/wiki/Caspian.

Wilks, D.S., 1995. Statistical Methods in the Atmospheric Sciences: An Introduction. Academic Press, pp: 467.

Zhang, Q.H., K.H. Lau, H.Q. Wang and S.J. Chen, 2000. Numerical simulation on mesoscale convective system along Mei-Yu front in Southern China. Chin. Sci. Bull., 45 (22): 2093.

Zhang, Q.H., K.H. Lau, Y.H. Kuo and S.J. Chen, 2003. A numerical study of a mesoscale convective system over the Taiwan strait. Mon. Wea. Rev., 131 (6): 1150-1170. 